\title{
¿Cómo hacemos crecer una planta? Una indagación con niños de 3 años de educación infantil
}

\section{How do we grow a plant? An inquiry with 3-year-olds}

\author{
Ana M. ${ }^{a}$ Rodríguez Melero \\ CEIP Colmenarejo. Campanillas, Málaga, España. \\ anarodmel@gmail.com \\ M. a José Cáceres Ruiz, Antonio Joaquín Franco-Mariscal \\ Didáctica de las Ciencias Experimentales. Universidad de Málaga. Málaga, España. \\ mariajosecaceres.1996@uma.es, anjoa@uma.es
}

RESUMEN • La práctica científica de indagación se considera idónea para aprender ciencias en educación infantil. Este trabajo presenta una indagación sobre germinación y crecimiento de plantas implementada con niños de 3 ańos durante 12 días, en la que se fomenta la toma de decisiones, desde la elección de semilla hasta la forma de riego o el lugar más adecuado para el crecimiento. Se exploran los avances logrados y se halla que el $62,5 \%$ de los nińos reconocen la semilla y el agua como factores necesarios para el crecimiento, y el 37,5\% incluye además la luz solar. A pesar de que algunos niños reconocieron que es necesaria para la germinación materia viva, y no inerte, otros no avanzaron en este sentido. Estos logros son relevantes porque algunas de estas dificultades se mantienen a los 6-7 años, y en este caso algunos niños de 3 años fueron capaces de expresarlo de forma sistemática en sus conclusiones.

PALABRAS CLAVE: Indagación; Plantas; Educación infantil; Toma de decisiones.

ABSTRACT • Scientific inquiry is ideal for learning science in early childhood education. This paper presents an inquiry on germination and growth of plants implemented with children of 3 years old during 12 days, in which decision making is encouraged, from the choice of seed to the way of watering or the most suitable place for the growth. The progress made is explored finding that $62.5 \%$ of the children recognize seed and water as necessary factors for growth and $37.5 \%$ also include sunlight. Despite the fact that some children recognized that it is necessary living matter, and not inert, for the germination, others did not advance in this sense. These achievements are relevant because some of these difficulties remain at the age of 6-7 years, and in this case, some 3-year-old children were able to express it systematically in their conclusions.

KEYWORDS: Inquiry; Plants; Early childhood education; Decision making.

Recepción: mayo 2020 • Aceptación: octubre 2020

Rodríguez Melero, A. M., Cáceres Ruiz, M. J. y Franco-Mariscal, A. J. (2021). ¿Cómo hacemos crecer una planta? Una indagación con niños de 3 años de educación infantil. Enseñan- 


\section{INTRODUCCIÓN}

La literatura muestra un escaso número de investigaciones en didáctica de las ciencias experimentales en la etapa de educación infantil (en adelante, EI) (Monteira y Jiménez, 2019), a pesar de que estos estudios indican beneficios importantes para el aprendizaje de las ciencias (OCDE, 2012). Este aprendizaje se favorece porque los niños ${ }^{1}$ muestran desde pequeños una curiosidad importante por comprender la naturaleza y el mundo que los rodea, y en este afán por descubrir son capaces de experimentar, adquirir información, reflexionar, construir ideas y probarlas (Cañal, 2006; Peterson y French, 2008), desarrollando diferentes capacidades para indagar.

Investigaciones recientes con niños de EI (Cruz, García-Carmona y Criado, 2017; Hinojosa y Sanmartí, 2016) ponen de relieve que pueden adquirir un pensamiento lógico básico que les permite iniciarse en los procesos elementales de la ciencia, quedando cada vez más lejana la idea piagetiana de que los preescolares no son capaces de realizar razonamientos abstractos.

Desde la perspectiva de los maestros de EI, existen diferencias en su visión para abordar la enseñanza de las ciencias en el aula. Así, los maestros en formación inicial lo consideran una tarea compleja (Cantó, Pro y Solbes, 2016), mientras que los maestros en ejercicio indican que ciertas habilidades, como la observación, el planteamiento de preguntas o el pensamiento crítico, son viables en esta etapa y ayudan a los nińos a construir sus conocimientos científicos y su razonamiento, así como a crear actitudes positivas hacia las ciencias (Mazas, Gil, Martínez, Hervas y Muñoz, 2018).

En todo caso, la enseñanza de las ciencias en EI debe considerarse una oportunidad para iniciar su aprendizaje, por lo que es importante dotar a los maestros de herramientas para descubrir, interpretar e interactuar con el medio natural, valorarlo y cuidarlo (García-Carmona, Criado y Cañal, 2014). Una herramienta es la práctica científica de indagación, fundamental para el logro de la alfabetización científica, extendida considerablemente en las aulas a partir de las recomendaciones de la NRC (2000) y del informe Science Education Now (Rocard, 2007), y que se beneficia por el interés de los niños a edades tempranas por manipular, explorar y preguntar sobre fenómenos del mundo que los rodea (Worth y Grollman, 2003).

Como indican Cruz et al. (2017), el reto del profesorado es fomentar experiencias de indagación en EI para que los escolares tomen conciencia de que la ciencia es útil para conocer y comprender el mundo natural. Desde nuestro punto de vista, es necesario mostrar a los maestros experiencias de indagación en edades tempranas y los resultados que producen para introducirlos en esta práctica. Por ello, este trabajo muestra los resultados de una indagación sobre el crecimiento de las plantas con niños de 3 años, muy alejada de la actividad de sembrar una semilla siguiendo las instrucciones del maestro.

\section{MARCO TEÓRICO}

\section{La indagación en educación infantil}

La indagación es un proceso complejo de construcción de significados y modelos conceptuales coherentes, en el que los estudiantes formulan cuestiones, investigan para encontrar respuestas, comprenden y construyen nuevo conocimiento y comunican su aprendizaje a otros, aplicando el conocimiento de forma productiva a situaciones no familiares (European Comission, 2015, p. 68).

Según la American Association for the Advancement of Science (AAAS) (1998), la etapa de EI es la más adecuada para iniciar en el aprendizaje de las ciencias mediante indagación, al poderse trabajar la ciencia con grupos de niños que colaboren y respondan preguntas sobre el medio natural a la vez que

1. Este artículo utiliza lenguaje no sexista. Las referencias en género masculino se hacen por economía del lenguaje. 
comparten experiencias. Tratar contenidos de ciencias mediante la indagación implica relacionarlos con hechos perceptibles por el niño en su vida diaria, en temas como los animales (Romero, 2000), las plantas (Gómez y Ruiz, 2016), el agua y el aire (Burtscher, 2011), los cambios de estado (Cruz et al., 2017; Monteira y Jiménez, 2019) o la flotabilidad de objetos (Hsin y Wu, 2011), habituales de la etapa.

Las experiencias de indagación en EI son cada vez más habituales, y se centran solo en ciertas etapas o ciclos completos. Las experiencias realizadas por Siry y Max (2013) con niños entre 4 y 6 años revelaron cómo las investigaciones de los niños pueden ser mediadas por sus propias especulaciones y explicaciones para construir de forma colaborativa el conocimiento. Asimismo, una observación bien guiada por los maestros y discutida explícitamente presenta ventajas en el aprendizaje en la primera infancia (Monteira y Jiménez, 2016; Romero, 2017).

Respecto al manejo de variables, Strand y Klahr (2008) mostraron que los niños a edades tempranas son capaces de manipular una variable si el resto se mantiene constante. Asimismo, niños de 4 años pueden interpretar datos de covariación que sustentan una hipótesis, capacidad que aumenta de manera significativa a los 5 años, mientras que a los 6 años se observa una mejora en la comprensión de la experimentación (Piekny, Grube y Maehler, 2014).

Otro aspecto clave es la selección del enfoque de indagación para el aula, siendo muy utilizado el denominado "5E learning cycle» (Bybee et al., 2006), que organiza la enseñanza en cinco etapas: motivación-involucramiento, exploración-investigación, explicación, extensión-elaboración y evaluación. A pesar de la diversidad de enfoques (Rönnebeck, Bernholt y Ropohl, 2016), todos ellos presentan elementos comunes, recogidos en el enfoque de Franco-Mariscal (2015) como planteamiento de la indagación, manejo de la información, diseño, recogida y procesamiento de datos, análisis de datos y emisión de conclusiones, comunicación de resultados, y actitud crítica y trabajo en equipo. Desde nuestra perspectiva, un enfoque simplificado que incluya estas dimensiones puede ser un modelo adecuado para EI.

\section{Las plantas en educación infantil}

Las plantas son un tópico recurrente en EI, abordado principalmente a partir de instrucciones para conseguir germinar una planta desde una semilla (Fernández y Rodríguez, 2006), su cuidado en el aula (Del Valle, 2011) o en el huerto escolar (Aragón y Cruz, 2016).

Las ideas previas son bien conocidas y han sido exploradas mayoritariamente en niños de primaria. Diferentes estudios muestran que el entendimiento del concepto de planta es limitado (Boulter, Tunnicliffe y Reiss, 2003; Tunnicliffe, 2001). Una primera dificultad es no considerar a los vegetales como seres vivos (Bebbington, 2005), debido a que los niños tienen problemas para diferenciarlos de los inertes y suelen identificar solo al ser humano y los animales como seres vivos, atribuyéndoles el movimiento y la alimentación como principales características (Garrido, 2007). Otra dificultad se encuentra al nombrar las semillas, siendo habitual que a los 4 ańos conozcan el nombre de algunas y confundan otras (Fernández, Medrano y Bello, 2006).

Respecto al conocimiento de la anatomía de las plantas, entrevistas a niños malteses de 4-5 años revelaron que planta significaba algo pequeño, con tallo delgado, hojas y una flor (Gatt, Tunnicliffe, Borg y Lautier, 2007). Bartoszeck, Cosmo, Silva y Tunnicliffe (2015) analizaron las representaciones de niños brasileños cuando se les pedía dibujar qué pensaban que era una planta, y observaron que a los 3 años no comprendían la tarea, pero con 4 y 5 años eran capaces de representar una planta con flores (angiosperma con hojas, tallo o una gimnosperma con hojas, tronco y piñas). El estudio, realizado hasta los 10 años, mostró que muy pocos niños eran capaces de representar angiospermas de flores/ arbustos con hojas, tallos y raíces, o árbol de angiospermas con hojas, flores y/o fruto, tallo y raíces. Estos resultados coinciden con los obtenidos por Vicente (1994) para niños españoles de 6-7 años, que reconocen todas las partes de una planta excepto las raíces; indican que es necesario echar semillas en 
agua para que una planta crezca, y además necesitan agua, tierra y luz para vivir, aunque este último factor es poco citado. Asimismo, identifican las plantas con las flores (Vicente, 1994). Por otro lado, los niños de primaria afirman que las plantas se alimentan del suelo por las raíces, entendiendo que el agua es un alimento para ellas (Fernández y Rodríguez, 2006).

No obstante, son escasas las investigaciones centradas en la aplicación en el aula de propuestas relacionadas con el medio natural: plantaciones, clasificaciones de plantas, cuidado de estas, creaciones de huertos, etc., u otras enfocadas desde la indagación. A pesar de ello, la literatura recoge unas pocas indagaciones algo menos guiadas (Acosta et al., 2011; De la Blanca, Hidalgo y Burgos, 2013). Es el caso del estudio de Acosta et al. (2011), que plantea varias investigaciones sobre plantas con nińos de 4-5 años: cómo nacen, qué necesitan las semillas para germinar, cuáles son sus partes, el crecimiento hacia la luz, su clasificación, hojas y troncos de diversos árboles, etc. Los resultados de este estudio muestran una disparidad de opiniones a los 4-5 años en torno a que una semilla germine sin luz, sin tierra o sin agua, aunque la mayoría pensaba que no era posible. Para comprobar sus hipótesis siembran distintas semillas en tierra y sin tierra (en algodón), con agua y sin agua, y con luz y sin luz (dentro de una caja), manteniendo el resto de los factores fijos, y haciendo la observación tras una semana. El trabajo de De la Blanca et al. (2013) indica que niños de 4 años, a través de la manipulación de la semilla de aceituna, pueden establecer relaciones causa-efecto y verbalizar las consecuencias de las acciones sobre semillas y frutos, además de contribuir a valorar y respetar el entorno.

\section{Germinación y crecimiento de una planta}

Este apartado describe brevemente la germinación y el crecimiento de una planta, dos procesos fisiológicamente muy distintos, que puede ayudar a maestros de EI a abordar este tema en el aula.

La germinación depende de las reservas acumuladas en el endospermo de la semilla, y, por tanto, requiere de unas condiciones de humedad, pero no de luz solar, debido a que el crecimiento de los tejidos sucede a expensas de los tejidos de almacén y no requiere fotosíntesis. Sin embargo, el crecimiento de tallo y hojas, y que adquieran su color verde, depende de la cantidad de luz. En ausencia de luz, la planta puede llegar a crecer unos días, pero etiolada, es decir, con tallos blanquecinos largos y muy finos.

La intensidad del riego es una variable relativa relacionada con la evapotranspiración del día anterior. Por ello, no es necesario regar con mucha o poca cantidad de agua, sino con la necesaria para que el algodón esté húmedo. Para evitar anegar las raíces y permitir su oxigenación es conveniente hacer un agujerito en el fondo del recipiente.

\section{OBJETIVOS}

Los objetivos de este trabajo son:

1. Mostrar cómo llevar a cabo una secuencia de indagación relacionada con la germinación y crecimiento de plantas con niños de EI de 3 años.

2. Documentar el avance producido en la comprensión conceptual del crecimiento de una planta tras la indagación.

3. Fomentar la observación, realización de predicciones, experimentación, recogida de datos, toma de decisiones y emisión de conclusiones en niños de 3 años.

\section{METODOLOGÍA Y DISEÑO DE LA INVESTIGACIÓN}

Este estudio se enmarca en una perspectiva cualitativa y el diseño es un estudio de caso. 


\section{Participantes y contexto}

Los participantes son 8 estudiantes de EI de 3 años ( 5 niñas y 3 niños) del CEIP Colmenarejo de Campanillas (Málaga), su maestra y una alumna en prácticas del 4. ${ }^{\circ}$ curso del grado en EI de la Universidad de Málaga. El carácter limitado de la muestra permite realizar un mejor seguimiento de la indagación.

Las maestras tomaron como punto de partida las preguntas de los niños para desarrollar una indagación sobre plantas. Los niños habían sido criados en entornos diferentes y tenían distinto nivel de estimulación. Tenían distinta fluidez en el habla e intención comunicativa, poseyendo algunos todavía un lenguaje inmaduro con escasa comunicación (lengua de bebé), razón por lo que su participación en la asamblea fue desigual: 4 niños tuvieron participación alta (70 \% de los días) y otros 4 niños, media (50-60\%). La adquisición del lenguaje es un proceso de gran importancia en el desarrollo de los infantes, ya que de él depende el correcto funcionamiento de las áreas cognitiva, social, emocional y de los procesos de autorregulación de la conducta (Campo, 2009). Influye en el desarrollo de la inteligencia y el razonamiento, este último aspecto clave de la indagación.

El centro donde se desarrolló la investigación pertenece a una población rural muy pequeña de 700 personas de clase media-baja, bastante aislada y con carencias en servicios.

\section{Descripción de la experiencia}

La experiencia se realizó durante enero y febrero de 2020 en 12 días consecutivos, que incluían un fin de semana (días 6 y 7), y para la que se pidió colaboración de las familias. Se desarrolló en las fases de la figura 1, que corresponden a un modelo simplificado para EI del enfoque de indagación de FrancoMariscal (2015). Dos aspectos que cabe destacar de este ciclo de indagación son su carácter recursivo y la evolución en las ideas de la ciencia, desde las pequeñas a las grandes ideas (Harlen, 2010).

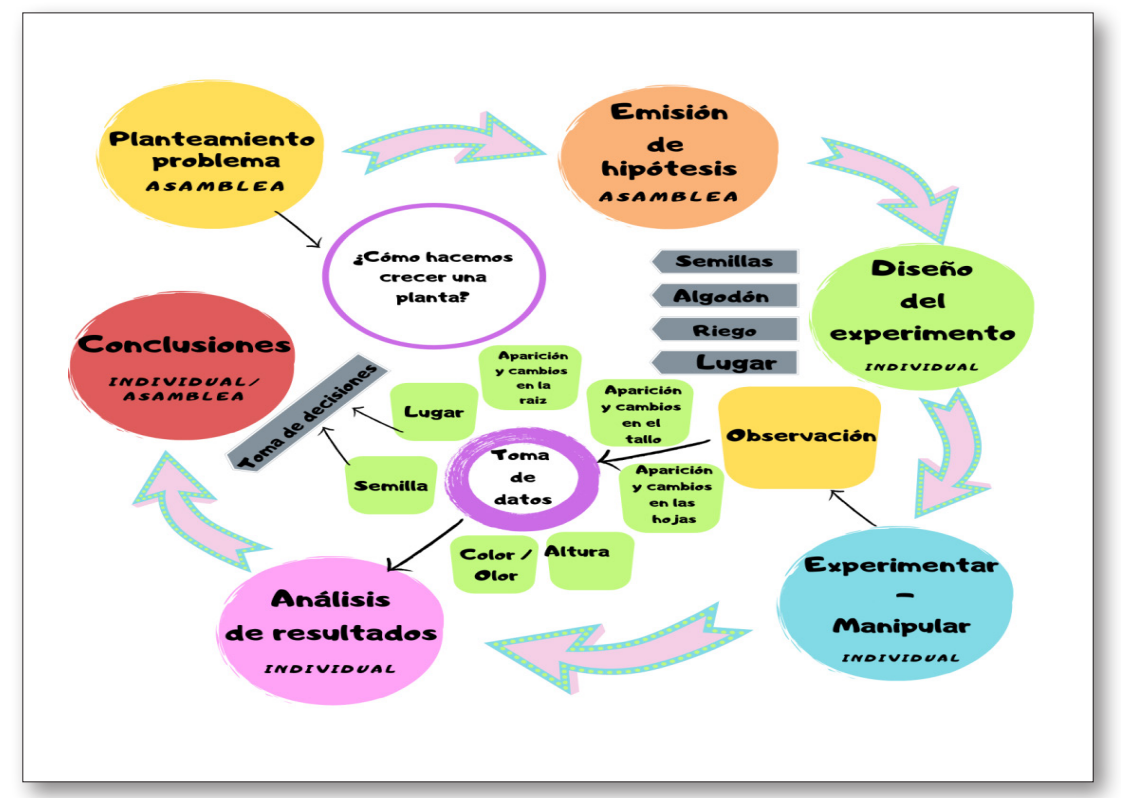

Fig. 1. Fases de la indagación.

En algunas actividades los niños debían tomar decisiones. Las posibles opciones se ofrecieron bastante pautadas debido a que la autonomía del niño es reducida a estas edades. En estas decisiones trabajaron de forma individual para permitir una mejor monitorización de la evolución de cada niño y evitar el 
aprendizaje social por medio de la observación y de la imitación de comportamientos. Para fomentar oportunidades de aprendizaje entre pares tras cada acción se hizo una puesta en común en asamblea.

\section{Fase 1. Planteamiento del problema y emisión de hipótesis}

En la asamblea, la maestra planteó cómo podía hacer más bonita su terraza, y concluyó que era buena idea poner plantas. Para que los niños pudieran emitir sus hipótesis preguntó: «¿Cómo hacemos crecer una planta?».

\section{Fase 2. Diseño del experimento}

Una vez emitidas las hipótesis, la maestra dio a cada niño un vaso de plástico y ofreció alternativas para que pudieran diseñar su experimento. En la asamblea vieron las distintas posibilidades de semillas que se podían elegir, pudiéndolas tocar y preguntar lo que quisieran sobre ellas. Se dedicó un tiempo a trabajar algunas propiedades, como tamaño, color o forma. Luego, la maestra apartó del grupo a los niños de uno en uno para que eligieran entre legumbres (garbanzos o lentejas) o materia inerte (Lacasitos o tizas).

Una vez escogida la semilla, se ofreció la posibilidad de mojar el algodón con agua. Por último, se indicaron posibles zonas del aula con diferente iluminación, donde podían colocar su vaso para que su semilla germinara. En sucesivos días los nińos seguirían tomando decisiones, de forma independiente, en las variables implicadas en una indagación con plantas (naturaleza de la semilla, forma de riego o ubicación).

\section{Fase 3. Experimentar-manipular}

Durante cada sesión se dedicaron 15 minutos al seguimiento individual de la planta. Cada niño debía observar su planta, explicar qué cambios observaba y tomar algunos datos (aparición y cambios en la raíz, tallo y hojas, altura del tallo, y color y olor de la planta). Los datos se recogieron en un panel visible en el aula y en el diario de observación de las maestras.

\section{Fase 4. Análisis de resultados y toma de decisiones}

Tras la observación y toma de datos, se preguntó a los niños qué querían hacer a su planta, dejando a su libre elección el riego o cambio de ubicación. De nuevo, cada nińo realizó estas acciones de forma individual, sin conocer lo que hacía el resto. Las diferentes acciones y cambios se recogieron en el panel, que luego se comentaba en grupo. Durante el primer fin de semana, llevaron las plantas a sus casas para continuar allí la indagación, informando a las familias de que no podían influir en sus acciones.

\section{Fase 5. Conclusiones}

Al finalizar la experiencia se pidió a cada niño individualmente que explicara qué había obtenido y qué creía que se debía hacer para que una planta creciera. Posteriormente se hizo una puesta en común.

Como se aprecia, la experiencia se diseñó siguiendo una secuencia de formulación de preguntas por las maestras, la elaboración de predicciones y la toma de decisiones por parte de los niños y su comprobación cada día. La tabla 1 presenta las actividades desarrolladas en cada fase, las preguntas realizadas, los objetivos que se pretenden y las competencias relacionadas con la indagación. 
Tabla 1.

Diseño de la indagación

\begin{tabular}{|c|c|c|c|c|}
\hline Fase & Actividades desarrolladas & Preguntas realizadas & Objetivos & $\begin{array}{c}\text { Competencias relacionadas } \\
\text { con indagación }\end{array}$ \\
\hline $\begin{array}{l}1 . \\
\text { Planteamiento } \\
\text { del problema } \\
\text { y emisión de } \\
\text { hipótesis }\end{array}$ & - Asamblea & $\begin{array}{l}\text { - ¿Qué puedo hacer para } \\
\text { que mi terraza esté más } \\
\text { bonita? } \\
\text { - ¿Cómo hacemos crecer } \\
\text { una planta? }\end{array}$ & $\begin{array}{l}\text { - Proponer soluciones a un } \\
\text { problema }\end{array}$ & $\begin{array}{l}\text { - Entender un problema } \\
\text { planteado } \\
\text { - Emitir hipótesis }\end{array}$ \\
\hline $\begin{array}{c}2 . \\
\text { Diseño del } \\
\text { experimento }\end{array}$ & $\begin{array}{l}\text { - Presentar semillas } \\
\text { - Elegir semillas } \\
\text { - Sembrar semillas en } \\
\text { un vaso con algodón } \\
\text { húmedo } \\
\text { - Ubicar el vaso en un } \\
\text { lugar }\end{array}$ & $\begin{array}{l}\text { - ¿Sabes qué es? } \\
\text { - ¿Cómo se llama? } \\
\text { - ¿Qué color/tamaño/ } \\
\text { forma tiene? } \\
\text { - ¿'Sabes que estamos } \\
\text { haciendo? } \\
\text { - ¿Cuántas semillas } \\
\text { quieres echar? } \\
\text { - ¿Quieres mojar tu } \\
\text { algodón? ¿Cómo? } \\
\text { - ¿Es importante el } \\
\text { sitio donde ponemos } \\
\text { la semilla? ¿Dónde } \\
\text { crecerá mejor? ¿Por } \\
\text { qué? }\end{array}$ & $\begin{array}{l}\text { - Conocer tipos de semillas } \\
\text { - Describir tamańo, color y } \\
\text { forma de semillas } \\
\text { - Reconocer que una planta } \\
\text { puede germinar a partir de } \\
\text { una semilla y no puede hacer- } \\
\text { lo a partir de materia inerte } \\
\text { - Contar semillas } \\
\text { - Comparar el número de } \\
\text { semillas añadidas en cada vaso } \\
\text { - Reconocer que una planta } \\
\text { necesita agua para germinar } \\
\text { - Reconocer que una planta } \\
\text { puede germinar en ausencia } \\
\text { de luz }\end{array}$ & $\begin{array}{l}\text { - Observar } \\
\text { - Describir } \\
\text { - Participar en el diseño } \\
\text { de experimentos } \\
\text { - Participar en la identi- } \\
\text { ficación de variables } \\
\text { - Manipular }\end{array}$ \\
\hline $\begin{array}{l}3 . \\
\text { Experimentar- } \\
\text { manipular }\end{array}$ & $\begin{array}{l}\text { - Sembrar semillas } \\
\text { - Regar una planta } \\
\text { - Cambiar el vaso de } \\
\quad \text { lugar }\end{array}$ & $\begin{array}{l}\text { - ¿Qué quieres hacer hoy } \\
\text { con tu vasito? } \\
- \text { ¿Es necesario regar } \\
\text { la planta? ¿Quieres } \\
\text { regarla hoy? } \\
- \text { ¿Es necesario cambiar } \\
\quad \text { el vaso de sitio? } \\
- \text { ¿Quieres ponerlo en } \\
\text { otro sitio? }\end{array}$ & $\begin{array}{l}\text { - Relacionar el número de } \\
\text { semillas ańadidas con mayores } \\
\text { posibilidades de germinación } \\
\text { - Reconocer que una planta } \\
\text { necesita agua para crecer } \\
\text { - Reconocer que una planta } \\
\text { no necesita abundante agua } \\
\text { para crecer, sino la cantidad } \\
\text { adecuada } \\
\text { - Reconocer que una planta } \\
\text { necesita luz solar para crecer } \\
\text { - Reconocer que un lugar con } \\
\text { mayor luz solar favorece el } \\
\text { crecimiento de una planta. }\end{array}$ & $\begin{array}{l}\text { - Observar } \\
\text { - Manipular } \\
\text { - Realizar experimentos }\end{array}$ \\
\hline $\begin{array}{c}4 . \\
\text { Análisis de re- } \\
\text { sultados y toma } \\
\text { de decisiones }\end{array}$ & $\begin{array}{l}\text { - Observar aparición y } \\
\text { cambios en raíz, tallo } \\
\text { y hojas } \\
\text { - Medir la altura del } \\
\text { tallo } \\
\text { - Contar número de } \\
\text { hojas } \\
\text { - Observar el color } \\
\text { de cada parte de la } \\
\text { planta } \\
\text { - Oler una planta }\end{array}$ & $\begin{array}{l}\text { - ¿Qué crees que le ha } \\
\text { salido a la planta? } \\
\text { ¿Cómo se llama? } \\
\text { - ¿Por qué crees que ha } \\
\text { salido? } \\
\text { - ¿Para qué crees que } \\
\text { sirve? } \\
\text { - ¿Cuántos hay? ¿Cuánto } \\
\text { mide? } \\
\text { - ¿Qué color tiene? } \\
\text { - ¿A qué huele? }\end{array}$ & $\begin{array}{l}\text { - Observar la raíz como primer } \\
\text { cambio en la planta } \\
\text { - Identificar y nombrar adecua- } \\
\text { damente raíz, tallo y hojas } \\
\text { - Reconocer que las plantas } \\
\text { crecen de día y de noche } \\
\text { - Apreciar que las plantas } \\
\text { tienen olor }\end{array}$ & $\begin{array}{l}\text { - Tomar datos } \\
\text { - Describir } \\
\text { - Medir } \\
\text { - Analizar resultados } \\
\text { - Comparar experimen- } \\
\quad \text { tos } \\
\text { - Tomar decisiones }\end{array}$ \\
\hline $\begin{array}{c}5 . \\
\text { Conclusiones }\end{array}$ & - Asamblea & $\begin{array}{l}\text { - ¿Qué has obtenido? } \\
\text { - ¿Ha crecido tu planta? } \\
\text { ¿Por qué? }\end{array}$ & $\begin{array}{l}\text { - Conocer los factores que } \\
\text { influyen en el crecimiento de } \\
\text { una planta }\end{array}$ & - Extraer conclusiones \\
\hline
\end{tabular}

El aspecto novedoso de este trabajo se encuentra en la edad tan temprana de los participantes y, sobre todo, en la realización de un seguimiento diario del proceso que les hace partícipes y obliga a tomar decisiones, no dirigidas por la maestra, aunque sean erróneas. Pensamos que esta experiencia puede ser útil para otros maestros de EI interesados en iniciar a sus escolares en la indagación. 


\section{Instrumentos de recogida y análisis de datos}

Los instrumentos utilizados para recoger la información fueron:

a) Respuestas orales de los niños mediante grabaciones de audio-vídeo durante la indagación, de forma individual y en asamblea.

b) Diario de observación de las maestras, que, actuando como investigadoras, recogieron los acontecimientos más destacados ocurridos en el aula.

c) Registro diario del seguimiento del proceso en un panel en el aula que incluía pictogramas que representaban los factores del crecimiento. Los niños anotaron con pegatinas algunos datos, mientras que otras observaciones fueron apuntadas por la maestra tras entrevistarlos.

Este trabajo se centra en el análisis del discurso del alumnado y en las interacciones entre participantes (Gee, 2005), siendo la principal fuente de datos las grabaciones de las sesiones, que fueron transcritas identificando a los nińos con seudónimos para guardar su anonimato. Se evitó que los niños se movieran por la clase para poder identificarlos en sus intervenciones. La ley de protección datos y derechos de imagen de los menores se garantizó a través de un consentimiento expreso solicitado a las familias. El análisis se realizó sin emplear software.

\section{DESARROLLO DE LA INDAGACIÓN Y RESULTADOS}

A continuación se describen los resultados de cada fase.

\section{Fase 1. Planteamiento del problema y emisión de hipótesis}

La primera sesión, de 1 hora, desarrolló las fases 1 y 2. La indagación comenzó un lunes con la maestra planteando este problema:

Maestra: «Estoy decorando mi casa y quiero poner más bonita mi terraza, pero no sé cómo, ¿qué puedo hacer?».

Niños: «Con plantas» [efusivamente y de forma mayoritaria].

Para explicitar sus hipótesis preguntó:

Maestra: «¿Cómo hacemos crecer una planta?»

Óscar: «Puedes comprar una maceta y tierra».

Patricia: «Hace falta una cosa mágica» [se refiere a semilla].

Bárbara: «Hay que regarla para que crezca una planta».

Maestra: «Muchas gracias. Se me ocurre que podéis ayudarme a obtener plantas para mi terraza».

Las hipótesis emitidas sobre qué se requiere para que una planta germine y crezca hacen referencia a la semilla, la tierra, el agua y el recipiente, ideas coincidentes con las de niños de primaria (Vicente, 1994).

\section{Fase 2. Diseńo del experimento}

Para ayudar a identificar las variables que intervienen en la germinación, la maestra siguió explicitando sus ideas en la asamblea. Presentó posibles semillas (lentejas, garbanzos, tizas blancas y de colores y 
Lacasitos), sin decir su nombre, para comprobar si elegían seres vivos o inertes, y preguntó sobre su tamaño, color y forma.

Maestra: «Os voy a presentar unas 'cositas' que podéis meter dentro del vasito. ¿¿Cuál queréis elegir?».

Óscar: «Lo que crece seguro son las lentejas... Mejor voy a coger estas bolitas blancas» [garbanzos].

A continuación, llamó a cada niño para que eligiera la semilla (figura 2), pudiendo coger las que desease, trabajando así el conteo. Se observó que identificaban las lentejas, pero no los garbanzos (Fernández et al., 2006), a los que denominaban «bolitas blancas» (7/8 niños).
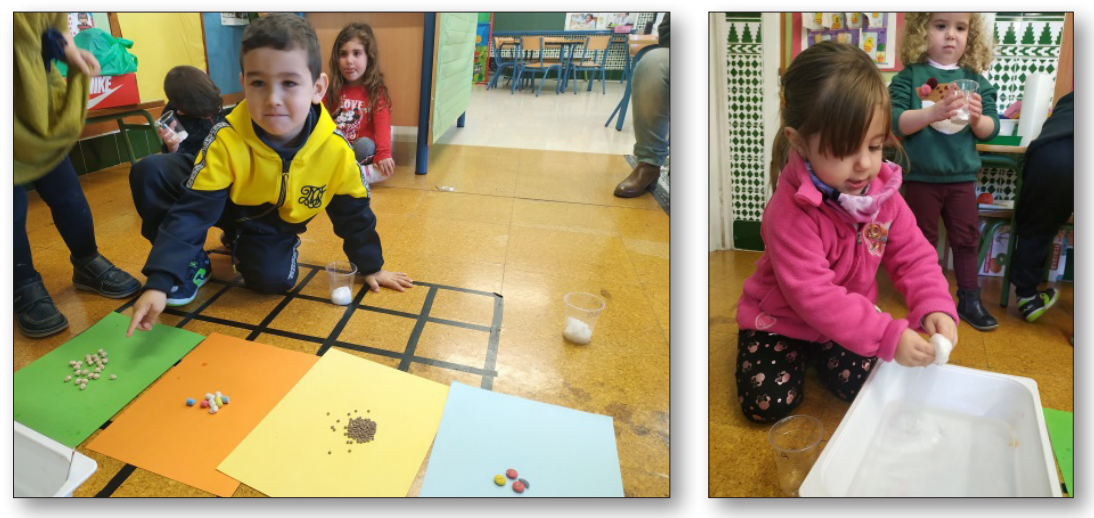

Fig. 2. Nińos eligiendo semillas (izquierda) y mojando el algodón (derecha).

Tres niños eligieron garbanzos y otros tres, lentejas. Una niña cogió dos Lacasitos y otra, cuatro trozos de tiza blanca. En total, seis niños eligieron seres vivos y dos, materia inerte.

Luego, se trabajó la siembra con algodón:

Maestra: «QQué puede servir que tengamos en clase parecido a una maceta?».

Bárbara: «Podemos usar esos vasos de plástico que hay encima de tu mesa seño».

La maestra repartió a cada niño un vaso, que intencionadamente había puesto en su mesa y a los que había hecho un pequeńo agujero en la base. Indicó que debían ponerles un trocito de algodón que podían mojar. Les acercó algodón y un barreńo con agua para que procedieran como desearan: con unas gotitas, sumergiéndolo completamente, mojándolo y estrujándolo o seco (figura 2). Cada niño explicó lo que había hecho en asamblea. El 50 \% mojó su algodón y lo metió en el vaso totalmente empapado, y el otro 50 \% lo estrujó para que perdiera algo de agua y lo metió húmedo en su vaso. Ningún niño optó por ponerlo seco. Estos datos son indicativos de que todos los niños asumen que las plantas necesitan agua para germinar.

Una vez sembrada la semilla, se planteó esta cuestión:

Maestra: «¿Dónde ponemos nuestro vasito? Podríamos ponerlo en la cornisa de la ventana, en la estantería junto a la ventana, dentro del armario y cerramos las puertas, o dentro de esa caja de zapatos con una pequeña rendija».

Cuatro niños lo pusieron en la ventana, dos en la estantería, una dentro del armario y otra dentro de la caja con rendija (figura 3). De 8 niños, 6 pensaban que las plantas requerían luz solar para germinar. Esto, probablemente, se debe al aprendizaje social, ya que muchos han visto plantas colocadas en zonas bien iluminadas. No obstante, se trata de un objetivo complejo porque los nińos de 3 años no diferencian entre germinación y crecimiento, pues entienden todo el proceso como crecimiento. 

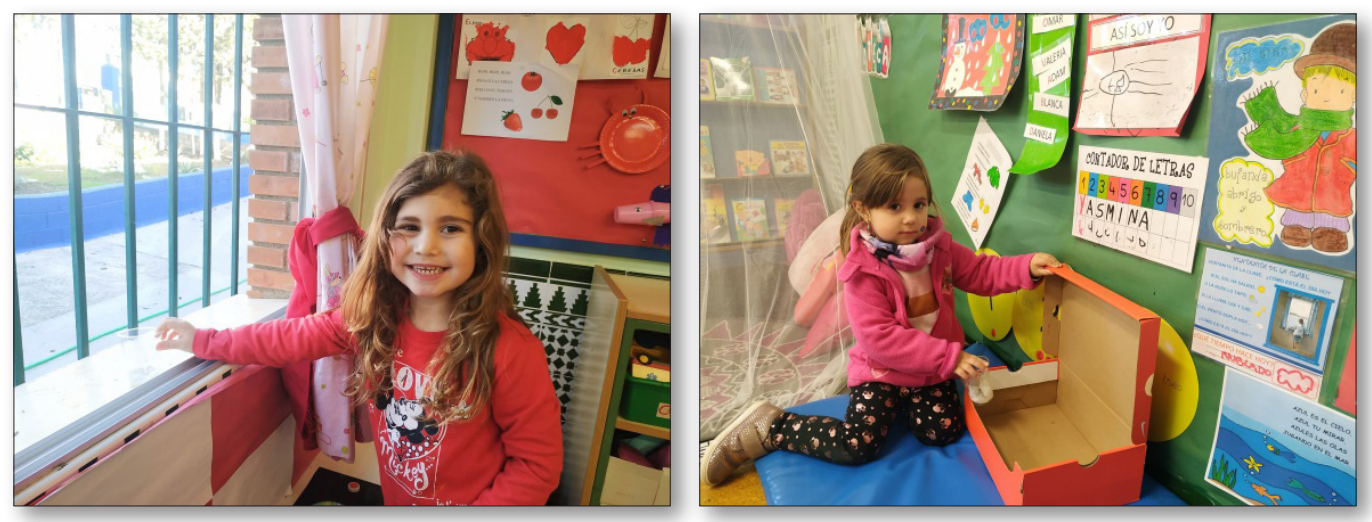

Fig. 3. Lugares elegidos por dos niñas para colocar el vaso con la semilla.

La tabla 2 recoge los resultados de la fase 2 en cuanto a las ideas previas manifestadas y los objetivos conseguidos y no conseguidos.

Tabla 2.

Resultados de la fase 2 sobre diseño del experimento

\begin{tabular}{|c|c|c|c|}
\hline & Ideas previas & Objetivos conseguidos & Objetivos no conseguidos \\
\hline $\begin{array}{l}\text { Sobre } \\
\text { la semilla }\end{array}$ & $\begin{array}{l}\text { - Se denominan «bolitas blancas» } \\
\text { a los garbanzos (7/8 niños) } \\
\text { - Una planta puede germinar a } \\
\text { partir de una tiza o un Lacasito } \\
\text { (2/8 nińos })\end{array}$ & $\begin{array}{l}\text { - Reconocer que una planta pue- } \\
\text { de germinar a partir de una se- } \\
\text { milla (lenteja o garbanzo) }(6 / 8 \\
\text { niños) }\end{array}$ & $\begin{array}{l}\text { - Reconocer que una planta no } \\
\text { puede germinar a partir de ma- } \\
\text { teria inerte ( } 2 / 8 \text { niños })\end{array}$ \\
\hline $\begin{array}{l}\text { Sobre } \\
\text { la influencia } \\
\text { de la luz }\end{array}$ & $\begin{array}{l}\text { - Una planta puede germinar en } \\
\text { un armario o en el interior de } \\
\text { una caja ( } 2 / 8 \text { niños })\end{array}$ & $\begin{array}{l}\text { - Reconocer que una planta pue- } \\
\text { de germinar en ausencia de luz } \\
\text { ( } 2 / 8 \text { niños) }\end{array}$ & $\begin{array}{l}\text { - Reconocer que una planta pue- } \\
\text { de germinar en ausencia de luz } \\
\text { (6/8 niños) }\end{array}$ \\
\hline $\begin{array}{l}\text { Sobre } \\
\text { el agua }\end{array}$ & $\begin{array}{l}\text { - El algodón debe ponerse empa- } \\
\text { pado (4/8 niños) }\end{array}$ & $\begin{array}{l}\text { - Reconocer que una planta ne- } \\
\text { cesita agua para germinar }(8 / 8 \\
\text { niños) }\end{array}$ & \\
\hline
\end{tabular}

Cabe destacar que ningún niño se dio cuenta del agujerito en el fondo del vaso, relacionado con la oxigenación de las raíces, un objetivo más avanzado que se podría plantear en primaria.

\section{Fase 3. Experimentar-manipular}

Las fases 3 y 4 se desarrollaron en los días sucesivos. El día 2 (martes) tuvo lugar este diálogo en la asamblea:

Maestra: «Todos los días vamos a dedicar el principio de la clase a hacer un seguimiento del crecimiento de vuestra planta. Os preguntaré uno a uno qué quieres hacer hoy con vuestro vasito».

Isabela: «Podemos ver si nuestra planta ha crecido».

Manuela: «No le hacemos nada, la dejamos ahí».

Óscar: «Podemos regalarla con mucha agua para que crezca supergrande» [la riega bajo el grifo].

Óscar: «Voy a ponerla en la ventana mejor para que le caiga agua de la lluvia y se ponga grande».

Alan: «Quiero cambiarla de sitio». 
Como se observa, el día después de la siembra, y donde evidentemente no había sucedido nada, hubo distintas opiniones entre los niños respecto a qué debían hacer con su planta. Algunos mantenían esperar, mientras que otros le echaron más agua -que no era necesario- o la cambiaron de sitio sin motivo.

El día 3 (miércoles) observaron, con sorpresa, los primeros cambios. Como respuesta a qué hacemos hoy con el vasito, Alan quiso cambiarlo de sitio de nuevo, y al cogerlo se dio cuenta de que algo había sucedido.

Alan: «Seño, le ha salido...».

Maestra: «¿Qué ha salido?».

Alan: [se queda callado y pensativo sin saber decir el cambio (aparición de raíces)].

Bárbara [se acerca y dice espontáneamente]: «iLe han salido semillas, no la cambies de sitio Alan!».

Patricia abre su caja y expresa con asombro:

Patricia: «Seño, ¡ha cambiado! No está igual que ayer, ¿qué es esto?».

Maestra: «Qué crees que puede ser?».

Patricia: «Quiero echarle bolitas blancas ahora [garbanzos] y también quiero regalarla con un chorrito en el grifo. Seño. ayúdame para que salga poquita agua».

Los diálogos mostrados ponen de manifiesto que los niños son capaces de apreciar los primeros cambios en su planta, pero no de nombrar y reconocer las partes de una planta, difíciles de identificar en los primeros momentos (figura 4), como recoge la literatura para escolares de mayor edad (Vicente, 1994).
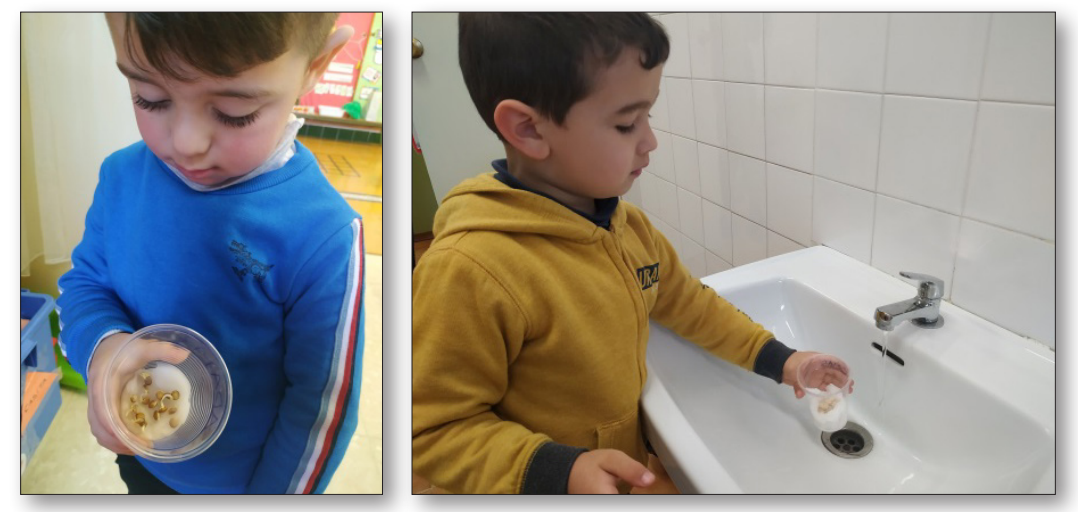

Fig. 4. Observando la aparición de raíces (izquierda) y regando con abundante agua (día 3).

A partir de este día los cambios se fueron anotando en el panel de la clase, que se elaboró con pictogramas para las variables implicadas (figura 5). Los niños colocaban una pegatina circular roja si regaban la planta y en sucesivos días tomaban datos que apuntaba la maestra. 


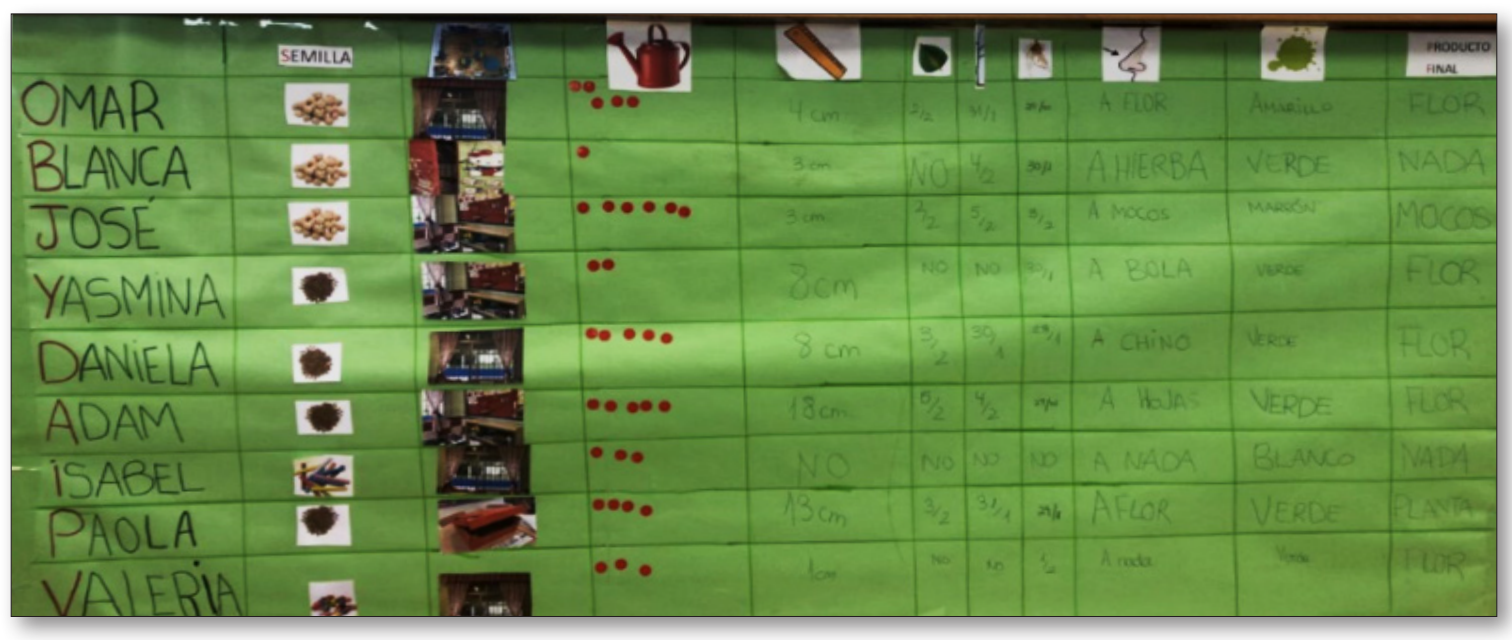

Fig. 5. Panel donde los niños registran la evolución de su planta.

La tabla 3 recoge los resultados de la fase 3 sobre experimentar y manipular.

Tabla 3.

Resultados de la fase 3 después de 3 días

\begin{tabular}{|c|c|c|c|}
\hline & Ideas previas & Objetivos conseguidos & Objetivos no conseguidos \\
\hline Sobre la semilla & $\begin{array}{l}\text { - Una planta puede germinar a } \\
\text { partir de una tiza o un Laca- } \\
\text { sito ( } 2 / 8 \text { niños })\end{array}$ & $\begin{array}{l}\text { - Relacionar el número de se- } \\
\text { millas añadidas con mayores } \\
\text { posibilidades de germinación } \\
\text { (1/8 niños) }\end{array}$ & $\begin{array}{l}\text { - Reconocer que una planta no } \\
\text { puede germinar a partir de } \\
\text { materia inerte }(2 / 8 \text { nińos })\end{array}$ \\
\hline $\begin{array}{l}\text { Sobre la influencia } \\
\text { de la luz }\end{array}$ & $\begin{array}{l}\text { - Una planta puede crecer en } \\
\text { un armario o en el interior de } \\
\text { una caja ( } 2 / 8 \text { nińos })\end{array}$ & $\begin{array}{l}\text { - Reconocer que una planta } \\
\text { necesita luz solar para crecer } \\
\text { (6/8 nińos). } \\
\text { - Reconocer que un lugar con } \\
\text { mayor luz solar favorece el } \\
\text { crecimiento de una planta } \\
\text { (1/8 niños) }\end{array}$ & $\begin{array}{l}\text { - Reconocer que un lugar con } \\
\text { mayor luz solar favorece el } \\
\text { crecimiento de una plan- } \\
\text { ta ( } 2 / 8 \text { niños mantienen la } \\
\text { planta en zonas oscuras) }\end{array}$ \\
\hline Sobre el agua & $\begin{array}{l}\text { - Se requiere abundante agua } \\
\text { para que crezca una planta } \\
\text { (4/8 niños) }\end{array}$ & $\begin{array}{l}\text { - Reconocer que una planta } \\
\text { necesita agua para crecer }(8 / 8 \\
\text { nińos) }\end{array}$ & $\begin{array}{l}\text { - Reconocer que una planta no } \\
\text { necesita abundante agua para } \\
\text { crecer, sino la cantidad ade- } \\
\text { cuada ( } 4 / 8 \text { niños) }\end{array}$ \\
\hline $\begin{array}{l}\text { Sobre las partes de } \\
\text { la planta }\end{array}$ & $\begin{array}{l}\text { - Aparición de raíces entendi- } \\
\text { da como aparición de semi- } \\
\text { llas ( } 1 / 8 \text { niños })\end{array}$ & $\begin{array}{l}\text { - Observar la raíz como primer } \\
\text { cambio en la planta ( } 2 / 8 \text { ni- } \\
\text { ños) }\end{array}$ & $\begin{array}{l}\text { - Observar la raíz como primer } \\
\text { cambio en la planta (1/8 ni- } \\
\text { ńos) }\end{array}$ \\
\hline
\end{tabular}

\section{Fase 4. Análisis de resultados y toma de decisiones}

Aunque las fases 3 y 4 se solapan en el tiempo, a partir del día 4 (jueves) esta fase tomó más protagonismo. Este día afloró la idea previa de que el crecimiento de una planta se produce de forma rápida. Al comprobar que no era así, los niños realizaron acciones para acelerar el crecimiento. Una de ellas fue añadir más lentejas, pensando que de ese modo las estaban alimentando. 
Maestra: «Qué quieres hacerle a tu planta?».

Patricia: «Quiero echarle más lentejas».

Maestra: «¿Para qué?».

Patricia: «Necesitan comida».

Otros niños optaron por regar con más agua, indicio que muestra que para ellos es el principal factor del crecimiento, independientemente de la cantidad, o que se haya regado el día antes, como recogen estos diálogos:

Juan: «Hoy quiero echarle mucha agua a mi planta» [comentario tras comprobar que no hay cambios].

Maestra: «Adelante».

Juan: «Debajo del grifo no la quiero poner. Le voy a echar agua con un vaso».

Manuela: «iMi planta sigue igual!».

Maestra: «¿Quieres hacerle algo hoy a tu vasito?».

Manuela: «Quiero echarle mucha agua» [al llegar al lavabo cambia de opinión].

Manuela: «Mejor le voy a echar agua con una cucharita» [finalmente echa mucha agua].

Manuela: "Quiero que mi vasito siga en la ventana».

Bárbara corrió muy ilusionada a abrir el armario donde se encontraba su planta, y su cara cambió rápidamente al comprobar que no se habían producido cambios, proponiendo ubicarla junto a la ventana, que era el lugar donde el día anterior habían crecido las raíces de otras plantas y que recordaba de la asamblea:

Bárbara: «¡Ay! ¡La mía no se ha convertido...! Quiero cambiarla de sitio».

Maestra: «iA dónde la quieres poner?».

Bárbara: «La quiero poner ahora en la ventana».

Las dos niñas que habían sembrado materia inerte, al comprobar que no había cambios, tomaron decisiones diferentes. La niña que había sembrado tizas decidió ańadir una gran cantidad de agua, llenando el vaso hasta el borde, y guardarla dentro del armario. La niña que elegió Lacasitos añadió lentejas en el mismo vaso, y la dejó en el mismo lugar, constatando que se requiere materia viva para germinar.

Las acciones realizadas el día 5 (viernes) volvieron a confirmar el agua como elemento esencial del crecimiento, sin tener en cuenta cantidades y aflorando la idea de que se debe regar cada día.

Juan: «Le voy a echar un poco de agua con las manos». [Deja su vaso en la estantería].

Manuela, Alan y Victoria: «iQuiero echarle mucha agua!». [Cambian a la ventana].

Isabela [Vaso con tizas]: «Mi planta no ha hecho nada. Hay que echarle más agua». [Deja el vaso en la ventana].

Como se observa, algunos niños dieron preferencia al lugar más cercano a la luz.

Otros niños apreciaron cambios, que describieron de esta manera:

Patricia: «Se están rompiendo las bolitas [garbanzos] un poquito y está saliendo algo». [La riega y deja en el mismo sitio, la caja de zapatos].

Al llegar el fin de semana, cada niño se llevó su vasito a casa junto a una nota para las familias, donde se explicaba la indagación que estaban realizando y se informaba de que no debían proporcionarles ningún tipo de información sobre el proceso de germinación y crecimiento de una planta, sino dejar hacer a su hijo las acciones que desease. 
El día 8 (lunes), tras el fin de semana, solo la niña que tenía Lacasitos y lentejas en su vaso trajo una nota de su madre, explicando las acciones realizadas: regarla cada día y ponerla en el patio de su casa.

Maestra: «¿Por qué pusiste el vaso en el patio? ¿'Tiene tu madre otras plantas allí?».

Victoria: «No. Mi abuela tiene sus plantas en el patio».

Se valora muy positivamente la colaboración de padres y hermanos en la indagación, que permitió que la niña aprendiera a descubrir por sí sola, aun sabiendo que tenía sembrados Lacasitos y que de ellos no iba a germinar nada.

No ocurrió lo mismo con la niña que tenía tizas, que llegó diciendo lo siguiente:

Isabela: «Mi mamá me ha dicho que las tizas no crecen nada».

Maestra: «¿Qué hacemos entonces?».

Isabela: «La quiero poner en la ventana por si llueve que le caiga agua».

Como se observa, a pesar de la información, seguía teniendo esperanza de que las tizas podían germinar. La aparición de nuevas partes de la planta mostró el desconocimiento de sus nombres, como ilustran los casos de Juan, Óscar y Alan.

Maestra: «¿Crees que ha crecido tu planta este fin de semana?».

Juan: «¿Le han crecido un de esto?» [refiriéndose al tallo].

Maestra: «¿Tú que piensas?».

Juan: «Se ha abierto un poquito y quiero echarle mucha agua». [Abre el grifo y llena de agua hasta el borde].

Maestra: «¿Dónde la vas a poner?».

Juan: «La quiero poner en la ventana porque tiene mucha agua». [Era un día muy caluroso].

Se sigue repitiendo el uso/abuso del agua para favorecer el crecimiento, y en esta ocasión se relaciona la ventana como un lugar donde se producirá la evaporación del agua de forma más rápida.

Óscar llegó diciendo a voces que le había salido una flor, cuando se trataba de la raíz y un pequeño tallo (figura 6).

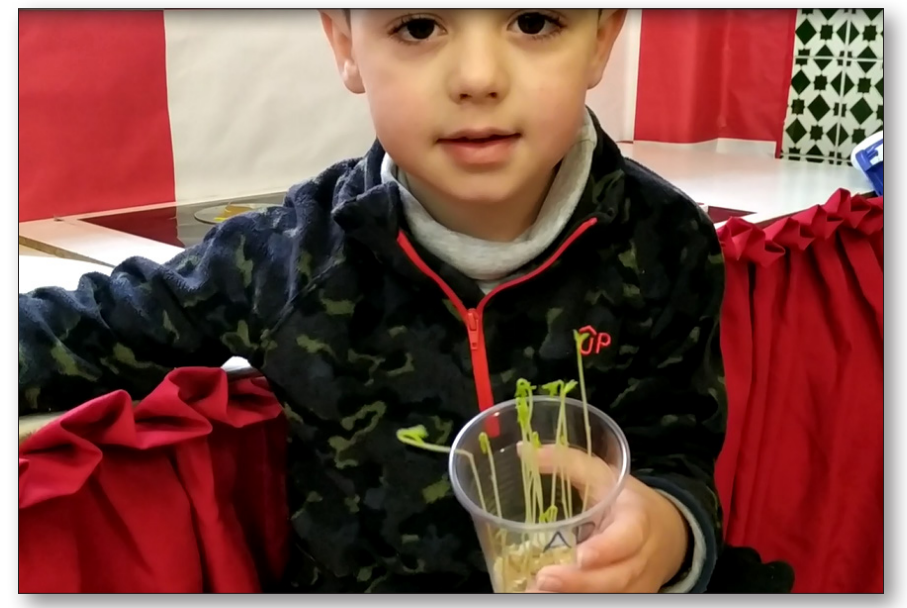

Fig. 6. Confusión de hojas con tallo (día 8). 
Alan, llegó feliz porque su planta estaba muy crecida, diciendo que le habían «nacido» hojas. Probablemente su familia tuvo algo que ver en esta conclusión, porque días antes su planta en clase ya había crecido y se quedaba callado al preguntarle sobre los cambios producidos.

El día 9 (martes) los niños no realizaron el seguimiento porque fueron de excursión. El día 10 (miércoles) confundieron la aparición de hojas con flores:

Óscar: «He echado agua estos días y por eso ha crecido una flor. Huele a flor».

Maestra: «¿Le quieres hacer algo?».

Óscar: «Quiero regarla un poquito, hoy solo con una cuchara».

Patricia, que siempre había guardado su vaso en la caja de zapatos con una pequeña rendija, al abrirla observó que su planta estaba muy grande (figura 7).

Patricia: «Tiene crecido».

Maestra: «¿Qué es lo que tiene crecido Patricia?».

Patricia: «Flores, seño, flores».

Patricia: «Quiero regalarla con zumo de naranja natural, procesado no. Natural porque es muy sano y bueno para la salud, y también ponerla en la ventana para que le caiga la lluvia».

Este último comentario se relaciona con otra actividad que la maestra realiza en clase (exprimir naranjas) para fomentar hábitos de vida saludable e incentivar el consumo de zumo natural frente al procesado. De ella, se deducen dos ideas. Por un lado, cualquier líquido distinto de agua puede ser bueno para el crecimiento y, por otro lado, si el zumo natural es bueno para los niños, también lo será para las plantas.

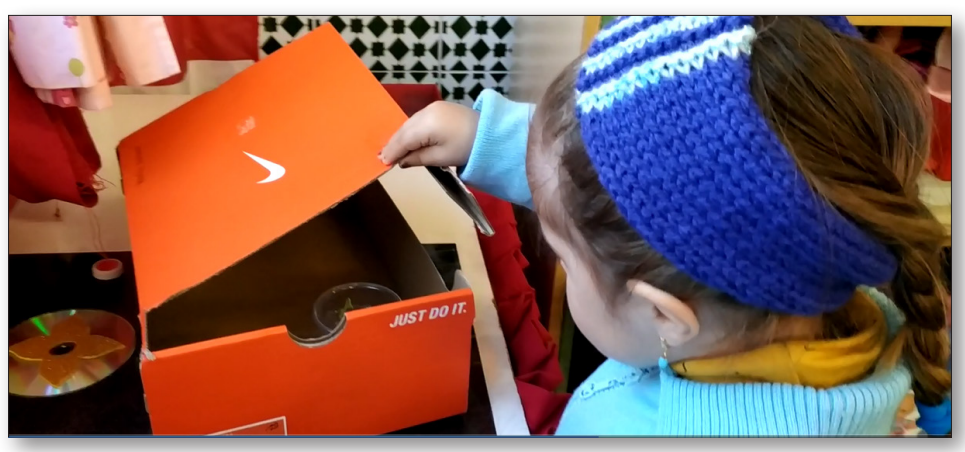

Fig. 7. Nińa observando su planta en el interior de una caja (día 10).

El crecimiento de la planta en el interior de la caja fue cuestión de debate en la asamblea de ese día porque algunos nińos pensaban que en esas condiciones no podía crecer.

Otro niño observó la aparición de nuevos elementos en la planta, pero desconocía su nombre:

Alan: «A mi planta le han nacido hojas. Voy a regarla, pero muy poco, con un tapón».

La aparición de raíces blancas en la planta de Juan, tras haberla tenido en su casa, le hace pensar que el lugar donde se ubique la planta es muy importante, por lo que pide llevársela de nuevo a casa.

Juan: «Ha nacido algo de mis 'bolitas'. Parecen mocos [se refiere a la raíz]. ¿̨Puedo llevármela otra vez a casa para echarle agua allí?». 
Isabela aún no había constatado que sus tizas no crecen y pensaba que era por falta de agua.

Isabela: «Está muy seca. Quiero echarle agua porque no crece».

El día 11 (jueves) siguieron apreciando y explicando nuevos cambios que se iban produciendo (tamańo, color, etc.). La mayoría asociaba el crecimiento a la presencia de luz y agua. Asimismo, reconocían que se debía añadir la cantidad de agua que la planta requiriese en cada momento, evidenciado por el uso de objetos de menor capacidad y la observación de que algunos vasos contenían agua del día anterior:

Manuela: «Mi planta se está poniendo verde porque siempre la pongo en la ventana, y hoy también quiero echarle agua, pero poca, con una cuchara».

Alan: «Mi planta tiene muchas hojas. Quiero regarla con un tapón». [La pone en la ventana].

Óscar: «Como la he regado le han salido flores, así que hoy también le quiero echar agua con un tapón y ponerla en la ventana».

Otro descubrimiento importante fue:

Victoria: «Las plantas crecen de día y de noche». [Echa mucha agua y pone en la ventana].

El agua también parece ser la solución para revivir plantas enfermas:

Juan: «Mi planta está llena de 'mocos’ porque está malita». [Echa agua con un tapón y la pone en la estantería].

El día 12 (viernes) se trabajó el olor, y encontraron dificultades para describirlo.

Maestra: «¿A qué huele nuestra planta?».

Alan: «Huele a hojas». [Riega con un tapón].

Patricia: «Huele a flor». [Echa agua con un tapón y coloca en la ventana].

Bárbara: «Huele a bola» [garbanzos]. [Riega bajo el grifo y guarda en el armario].

Los tres niños a los que no le había crecido su planta, bien por haber sembrado materia inerte, bien por haberla regado con demasiada agua, ofrecían estas explicaciones:

Isabela [tizas]: «Aunque le echo mucha agua, mi planta no crece».

Bárbara: «No ha crecido porque por la tarde no le eché agua». [Vuelve a regarla y la coloca en la ventana].

Juan: «Mi planta está mala. Le hace falta zumo».

La tabla 4 resume los principales resultados obtenidos en esta fase. 
Tabla 4.

Resultados en la fase 4 de análisis de datos y toma de decisiones.

\begin{tabular}{|c|c|c|c|}
\hline & Ideas previas & Objetivos conseguidos & Objetivos no conseguidos \\
\hline Sobre la semilla & $\begin{array}{l}\text { - El crecimiento de una } \\
\text { planta es un proceso rápido } \\
\text { (esta idea aparece el día } 4) \\
\text { (7/8 niños) } \\
\text { - Una planta puede germi- } \\
\text { nar a partir de una tiza (se } \\
\text { mantiene durante toda la } \\
\text { indagación) (1/8 niños) } \\
\text { - Las semillas son el alimento } \\
\text { para que una planta crezca } \\
\text { (8/8 nińos) }\end{array}$ & $\begin{array}{l}\text { - Relacionar el número de } \\
\text { semillas añadidas con ma- } \\
\text { yores posibilidades de ger- } \\
\text { minación (3/8 niños) (esta } \\
\text { idea aparece el día 3) } \\
\text { - Reconocer que las plantas } \\
\text { crecen de día y de noche } \\
\text { (esta idea aparece el día 11) } \\
\text { (1/8 niños) }\end{array}$ & $\begin{array}{l}\text { - Reconocer que una planta } \\
\text { no puede germinar a partir } \\
\text { de materia inerte (se man- } \\
\text { tiene durante toda la inda- } \\
\text { gación) ( } 1 / 8 \text { nińos) }\end{array}$ \\
\hline $\begin{array}{l}\text { Sobre la } \\
\text { influencia de } \\
\text { la luz }\end{array}$ & $\begin{array}{l}\text { - Una planta puede crecer en } \\
\text { el interior de una caja (se } \\
\text { mantiene durante toda la } \\
\text { indagación) ( } 1 / 8 \text { niños) }\end{array}$ & $\begin{array}{l}\text { - Reconocer que una planta } \\
\text { necesita luz solar para cre- } \\
\text { cer ( } 7 / 8 \text { niños) } \\
\text { - Reconocer que un lugar } \\
\text { con mayor luz solar favore- } \\
\text { ce el crecimiento (elección } \\
\text { de ventana. Día 4: } 2 / 8 \text { ni- } \\
\text { nóos; día 5: 4/8 nińos; día } \\
\text { 8: } 6 / 8 \text { nińos; día } 11: 7 / 8 \\
\text { niños) }\end{array}$ & $\begin{array}{l}\text { - Reconocer que un lugar } \\
\text { con mayor luz solar favo- } \\
\text { rece el crecimiento de una } \\
\text { planta (se mantiene duran- } \\
\text { te toda la indagación) (1/8 } \\
\text { niños mantienen la planta } \\
\text { en zonas oscuras) }\end{array}$ \\
\hline Sobre el agua & $\begin{array}{l}\text { - Hay que regar con abun- } \\
\text { dante agua para que crezca } \\
\text { una planta }(5 / 8 \text { niños) } \\
\text { - El zumo de naranja pue- } \\
\text { de ser bueno para el cre- } \\
\text { cimiento de una planta al } \\
\text { igual que para nińos (día } \\
\text { 10) ( } 1 / 8 \text { niños) }\end{array}$ & $\begin{array}{l}\text { - Reconocer que una planta } \\
\text { necesita agua para crecer } \\
\text { (8/8 nińos) } \\
\text { - Reconocer que una planta } \\
\text { no necesita abundante agua } \\
\text { para crecer, sino la cantidad } \\
\text { adecuada (8/8 nińos) } \\
\text { partir del día } 11)\end{array}$ & $\begin{array}{l}\text { - Reconocer que una planta } \\
\text { no necesita abundante agua } \\
\text { para crecer, sino la cantidad } \\
\text { adecuada ( } 8 / 8 \text { niños) (hasta } \\
\text { día 10) }\end{array}$ \\
\hline $\begin{array}{l}\text { Sobre las partes } \\
\text { de la planta }\end{array}$ & $\begin{array}{l}\text { - Una planta está formada } \\
\text { por hojas y flores ( } 5 / 8 \text { ni- } \\
\text { ños). } \\
\text { - Raíz y tallo se denominan } \\
\text { hoja o flor (a partir del día } \\
\text { 8) ( } 2 / 8 \text { niños) } \\
\text { - Las hojas se denominan flo- } \\
\text { res (a partir del día } 8)(1 / 8 \\
\text { nińos) }\end{array}$ & $\begin{array}{l}\text { - Apreciar que las plantas tie- } \\
\text { nen olor (7/8 niños) }\end{array}$ & $\begin{array}{l}\text { - Identificar y nombrar ade- } \\
\text { cuadamente raíz, tallo y } \\
\text { hoja ( } 4 / 8 \text { niños) }\end{array}$ \\
\hline
\end{tabular}

La figura 8 resume los logros conseguidos en cuanto a los distintos factores que influyen en el crecimiento de una planta. Se observa cómo la frecuencia inicial de nińos (6/8) que reconoce que una semilla es necesaria para la germinación aumenta el día 4 (7/8), mientras que, de 8 niños, 1 mantiene durante toda la indagación que la materia inerte puede germinar. En cuanto a la luz solar, los niños se dieron cuenta con el paso de los días de que es un factor clave del crecimiento (7/8), y a lo largo de la indagación aumentó el número de niños que cambió su vaso a la ventana, el lugar de la clase con mayor 
iluminación. No obstante, 1/8 de niños piensan que una planta puede crecer en la oscuridad. El uso de agua es un factor considerado por todos los niños durante la indagación, probablemente favorecido por la acción inicial de mojar el algodón. Sin embargo, 5/8 niños emplean grandes cantidades de agua durante gran parte de esta, sin ser conscientes la mayoría, hasta el día 11, de que se requiere la cantidad necesaria en cada momento.

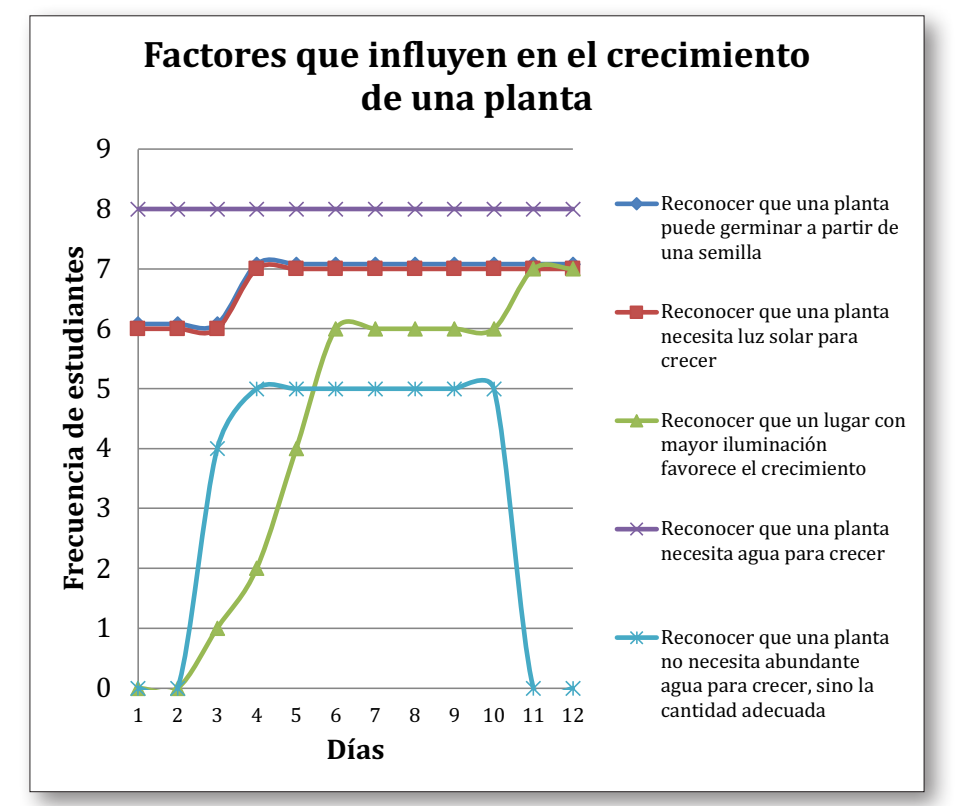

Fig. 8. Logros conseguidos para los distintos factores del crecimiento.

\section{Fase 5. Conclusiones}

En la última fase se intentó que los niños emitieran sus conclusiones de la indagación. Para ello, de forma individual, la maestra realizó la pregunta inicial: «¿Cómo hacemos crecer una planta?», y luego hizo una puesta en común. Las explicaciones individuales se pueden clasificar en 4 categorías, de mayor a menor adecuación:

- Categoría 1: Nińos que identifican semilla, presencia de luz y agua en cantidades adecuadas como factores del crecimiento (3/8):

Óscar: «Si quieres una planta tienes que coger un garbanzo, echarle agua, regarlo y ponerlo en una ventana para que se ponga grande».

Alan: «Lo he puesto en la ventana y le he echado agua y semilla».

Bárbara: «Mi planta [confunde con semilla] no ha crecido porque no le he echado agua, no se ha puesto verde, y la he guardado en el armario».

Como se observa, dos niños llevaron a cabo estas acciones, mientras que la tercera, a pesar de no haberlas realizado, es consciente de que son necesarias.

- Categoría 2: Niños que identifican semilla y agua (2/8) (5/8, porcentaje acumulativo):

Patricia: «Un vaso con una lenteja, mucha agua y sale una flor grande».

Victoria: «Le he echado agua y ha salido una flor». 
- Categoría 3: Niños que identifican el agua como único factor del crecimiento (2/8) (7/8, porcentaje acumulativo):

Manuela: «Hay que echarle agua y se pone grande».

Isabela: «La mía no ha crecido porque no le eché agua». [Indagación realizada con tizas].

- Categoría 4: Niños que no identifican ningún factor (1/8), a pesar de que el primer día se le dieron pistas, como mojar el algodón, acción que probablemente realizó por imitación:

Juan: «Hay que echarle mocos para que crezcan».

\section{CONCLUSIONES}

Este trabajo ha mostrado cómo llevar al aula una indagación sobre el crecimiento de plantas con niños de 3 años. El estudio detecta que algunas de las ideas recogidas en la literatura para primaria (Vicente, 1994) están presentes a esa edad, como la necesidad de una semilla, agua y luz para que una planta crezca. Creemos que los logros alcanzados con niños de 3 ańos son relevantes, por su capacidad de expresarlo de forma sistemática en sus conclusiones tras la indagación, ya que no todos los niños de 6 años son capaces de identificarlos (Vicente, 1994).

Es importante hacer conscientes a los niños de que solo se produce germinación a partir de materia viva. De las dos niñas que eligieron materia inerte, solo una fue consciente de la necesidad de una semilla, y por ello añadió lentejas a sus Lacasitos, mientras que la otra seguía pensando, tras la indagación, que de una tiza podía nacer una planta, manteniendo la idea de que los vegetales no son seres vivos (Garrido, 2007). Para movilizar esta idea se puede preguntar sobre las funciones de nutrición, relación y reproducción de seres vivos e inertes, así como si necesitan agua y oxígeno para vivir.

Otro aspecto problemático fue ajustar la cantidad adecuada de agua en cada momento. Para mejorarlo, sería conveniente debatir sobre esta necesidad o las consecuencias de anegar la planta. Del mismo modo, los comentarios acerca del uso de zumo natural para regar constituyen una línea futura que investigar.

El reconocimiento de la luz solar como responsable del crecimiento, pero no de la germinación, es un aspecto a seguir trabajando, pudiéndose potenciar ofreciendo a los niños zonas con mayor oscuridad, usando cajas con pequeńos agujeros que permitan crecer el tallo buscando la luz u observando el crecimiento con una fuente de luz artificial. Este tipo de experiencias permitirán mejorar distintas habilidades de indagación y, al acabar la etapa de EI, aumentar el porcentaje de niños capaces de identificar los factores asociados a la germinación y el crecimiento.

Otro tema que cabe reforzar es que los niños vayan adquiriendo el vocabulario científico implicado para que no confundan semilla y planta, nombres de semillas (Fernández et al., 2006) o las partes de la planta, y que no utilicen solo los términos flor y hoja. Este vocabulario procedimental básico se podría trabajar antes de la indagación.

La indagación también ha ayudado a que mejoren en los procesos científicos implicados, potenciando la observación y la descripción (aparición de nuevas partes de la planta, cambios producidos), la realización de predicciones, la experimentación (regando, cambiando el vaso de sitio), la recogida de datos (midiendo altura de tallos, contando hojas), la toma de decisiones y la emisión de conclusiones. Para llevar a cabo con éxito indagaciones a edades tan tempranas es muy importante que los maestros consigan implicar a los niños en las distintas etapas de la indagación, y darles protagonismo en la toma de decisiones en todo momento. Sin embargo, un aspecto que hay que reconsiderar es la frecuencia a la que se debe demandar al niño tomar decisiones, ya que la realización diaria ha invitado, especial- 
mente en los primeros días, cuando no se producían cambios, a emprender en ciertos niños acciones innecesarias, que en algunos casos pudieron desligar la acción de su efecto.

Por otro lado, la colaboración de las familias en indagaciones que obligan el seguimiento en casa resulta esencial. Para conseguirlo, los maestros deben informarles del proyecto que está realizando su hijo y compartir el modo de trabajo sin interferencias.

Finalmente, queremos resaltar que esta experiencia se implementó con un número reducido de niños, por una parte, para poder hacer un seguimiento personalizado a diario y de sus decisiones con fines investigadores, y por otra, por la dificultad adicional que supone realizarla a estas edades con grupos más numerosos, principalmente por la escasa autonomía que manifiestan, lo que favorecería en algunos niños la repetición de acciones.

\section{AGRADECIMIENTOS}

Proyectos I+D+i del Plan Nacional EDU2017-82197-P y PID2019-105765GA-I00.

\section{REFERENCIAS BIBLIOGRÁFICAS}

Acosta, M. C., Carmona, M. C., Flores, A. M., Ridaura, E., Sánchez, M. C., Dela Torre, M., Vázquez, N. y Vela, R. (2011). Taller de ciencias: investigo... las plantas. Investigación en la Escuela, 74, 2334.

American Association for the Advancement of Science (AAAS) (1998). Blueprints for reform: Science, Mathematics and Technology Education. Nueva York: Oxford University Press. https://doi.org/10.1086/376057

Aragón, L. y Cruz, I. M. (2016). Del huerto ecológico universitario al aula de infantil: Experiencias educativas en torno a problemas ambientales en la etapa de infantil. Revista Internacional de Educación Preescolar e Infantil, 2(1), 41-48.

Bartoszeck, A. B., Cosmo, C. R., Silva, B. R. y Tunnicliffe, S. D. (2015). Concepts of plants held by young Brazilian children: An exploratory study. European Journal of Educational Research, 4(3), 105-117.

https://doi.org/10.12973/eu-jer.4.3.105

Bebbington, A. (2005). The ability of A-level students to name plants. Journal of Biological Education, $39(2), 63-67$.

https://doi.org/10.1080/00219266.2005.9655963

Boulter C., Tunnicliffe S. y Reiss, M. (2003). Probing Children's Understandings of the Natural World. En J. Lewis, A. Magro, L. Simmoneaux (Eds.), Biology Educations for the Real World: Student Teacher-Citizen, Proceedings IV ERIDOB Conference, Toulouse: Ecole Nationale de Formation Agronomique.

Burtscher, I. M. (2011). Pequeños-grandes cientificos. Experimentos con el agua, aire, los fenómenos atmosféricos, el sol y la luna y el tiempo. Madrid: Narcea.

Bybee, R., Taylor, J., Gardner, A., Van Scotter, P., Powell, J., Westbrook, A. y Landes, N. (2006). The BSCS 5E Instructional Model: Origins and Effectiveness. Science Education National Institutes of Health.

Campo, L. A. (2009). Características del desarrollo cognitivo y del lenguaje en niños de edad preescolar. Psicogente, 12(22), 341-351. 
Cantó, J., Pro, A. y Solbes, J. (2016). ¿Qué ciencias se enseñan y cómo se hace en las aulas de Educación Infantil? La visión de los maestros en formación inicial. Enseñanza de las Ciencias, 34(3), 25-50. https://doi.org/10.5565/rev/ensciencias. 1870

Cañal, P. (2006). La alfabetización científica en la infancia. Aula de Infantil, 33, 5-9.

Cruz, M., García-Carmona, A. y Criado, A. (2017).Aprendiendo sobre los cambios de estado en Educación Infantil mediante secuencias de pregunta-predicción-comprobación experimental. Enseñanza de las Ciencias, 35(3), 175-193.

https://doi.org/10.5565/rev/ensciencias.2336

De la Blanca, S., Hidalgo, J. y Burgos, C. (2013). Escuela infantil y ciencia: la indagación científica para entender la realidad circundante. Enseñanza de las Ciencias, extra, 979-983.

Del Valle, A. (2011). Las plantas. Aula de Infantil, 61, 25-28.

European Commission (2015). Science education for responsible citizenship. Luxemburgo: European Union.

https://doi.org/10.2777/13004

Fernández, R., Medrano, G. y Bello, L. (2006). Las actividades en el rincón de ciencias. Un pretexto para la globalización en la etapa infantil. Aula de Infantil, 29, 28-30.

Fernández, R. y Rodríguez, L. M. (2006). Los pequeños de cuatro años en el rincón de ciencias: Qué ven y qué dicen sobre el nacimiento de las plantas. Alambique, 49, 105-113.

Franco-Mariscal, A. J. (2015). Competencias científicas en la enseñanza y el aprendizaje por investigación. Un estudio de caso sobre corrosión de metales en secundaria. Enseñanza de las Ciencias, 33(2), 231-252. https://doi.org/10.5565/rev/ensciencias. 1645

García-Carmona, A.,Criado, A. M. y Cañal, P. (2014).Alfabetización científica en la etapa 3-6 años: un análisis de la regulación estatal de enseñanzas mínimas. Enseñanza de las Ciencias, 32(2), 131-149. https://doi.org/10.5565/rev/ensciencias. 817

Garrido, M. (2007). La evolución de las ideas de los niños sobre los seres vivos (tesis doctoral). A Coruña: Universidad A Coruña.

Gatt, S., Tunnicliffe, S. D., Borg, K. y Lautier, K. (2007). Young Maltese children's ideas about plants. Journal Biological Education, 41(3), 117-121. https://doi.org/10.1080/00219266.2007.9656080

Gee, J. P. (2005). An Introduction to Discourse Analysis: Theory and Method. Londres: Routlegde. https://doi.org/10.1017/S0047404512000322

Gómez, C. y Ruiz, J. R. (2016). El rincón de la ciencia y la actitud hacia las ciencias en Educación Infantil. Revista Eureka sobre Enseñanza y Divulgación de las Ciencias, 13(3), 643-666.

https://doi.org/10.25267/rev_eureka_ensen_divulg_cienc.2016.v13.i3.10

Harlen, W. (Ed.) (2010). Principios y grandes ideas de la educación en ciencias. Herts: Association for Science Education.

Hinojosa, J. y Sanmartí, N. (2016). Indagando en el aula de ciencias: primeros pasos. En 27 Encuentros Didáctica Ciencias Experimentales. Badajoz: Universidad de Extremadura. https://doi.org/10.12795/IE.2019.i99.02

Hsin, C. y Wu, H. J. (2011). Using scaffolding strategies to promote young children's scientific understandings of floating and sinking. Journal of Science Education and Technology, 20(5), 656-666. https://doi.org/10.1007/s10956-011-9310-7

Mazas, B., Gil, M. J., Martínez, B., Hervas, A. y Muñoz, A. (2018). Los niños y las niñas de infantil piensan, actúan y hablan sobre el comportamiento del aire y del agua. Enseñanza de las Ciencias, 36(1), 163-180.

https://doi.org/10.5565/rev/ensciencias.2320 
Monteira, S. F. y Jiménez, P. (2016). The practice of using evidence in kindergarten: The role of purposeful observation. Journal of Research in Science Teaching, 53(8), 1232-1258. https://doi.org/10.1002/tea.21259

Monteira, S. F. y Jiménez, M. P. (2019). ¿Cómo llega el agua a las nubes? Construcción de explicaciones sobre cambios de estado en educación infantil. Revista Eureka sobre Enseñanza y Divulgación de las Ciencias, 16(2), 2101 https://doi.org/10.25267/Rev_Eureka_ensen_divulg_cienc.2019.v16. i2.2101

National Research Council (NRC) (2000). Inquiry and the National Science Education Standards. A Guide for Teaching and Learning. Washington, D. C.: National Academy Press. https://doi.org/10.17226/9596

OCDE (2012). Education at a Glance 2012 Highlights (pp. 74-75). París: OECD. https://doi.org/10.1787/eag_highlights-2012-en

Peterson, S. M. y French, L. (2008). Supporting young children's explanations through inquiry science in preschool. Early Childhood Research Quarterly, 23(3), 395-408. https://doi.org/10.1016/j.ecresq.2008.01.003

Piekny, J., Grube, D. y Maehler, C. (2014). The development of experimentation and evidence evaluation skills at preschool age. International Journal of Science Education, 36(2), 334-354. https://doi.org/10.1080/09500693.2013.776192

Rocard, M. (2007). Science Education Now: A Renewed Pedagogy for the Future of Europe. Luxemburgo: European Union.

Romero, D. (2000). Los animales que viven con nosotros. Una experiencia en educación infantil. Investigación en la Escuela, 40, 77-86. https://doi.org/10.12795/IE.2000.i40.06

Romero, M. (2017). El aprendizaje por indagación: ¿existen suficientes evidencias sobre sus beneficios en la enseñanza de las ciencias? Revista Eureka sobre Enseñanza y Divulgación de las Ciencias, 12(2), 286-299. https://doi.org/10.25267/Rev_Eureka_ensen_divulg_cienc.2017.v14.i2.01

Rönnebeck, S., Bernholt, S. y Ropohl, M. (2016). Searching for a common ground-A literature review of empirical research on scientific inquiry activities. Studies in Science Education, 52(2), 161-197. https://doi.org/10.1080/03057267.2016.1206351

Siry, C. y Max, C. (2013). The collective construction of a science unit: Framing curricula as emergent from kindergarteners' wonderings. Science Education, 97(6), 878-902. https://doi.org/10.1002/sce.21076

Strand, M. y Klahr, D. (2008). Developing elementary science skills: Instructional effectiveness and path independence. Cognitive Development, 23(4), 488-511. https://doi.org/10.1016/j.cogdev.2008.09.005

Tunnicliffe, S. D. (2001). Talking about plants - comments of primary school groups looking at plants as exhibits in a botanical garden. Journal of Biological Education, 36(1), 27-34. https://doi.org/10.1080/00219266.2001.9655792

Vicente, A. (1994). Unidad didáctica: Las plantas. Aula de Innovación Educativa, 33, 84-97.

Worth, K. y Grollman, S. (2003). Worms, Shadows and Whirlpools: Science in the Early Childhood Classroom. Washington, DC: NAEYC. https://doi.org/10.1177/183693910302800411 


\title{
How do we grow a plant? An inquiry with 3-year-olds
}

\author{
Ana M. ${ }^{a}$ Rodríguez Melero \\ CEIP Colmenarejo. Campanillas, Málaga, España. \\ anarodmel@gmail.com \\ M. José Cáceres Ruiz, Antonio Joaquín Franco-Mariscal \\ Didáctica de las Ciencias Experimentales. Universidad de Málaga. Málaga, España. \\ mariajosecaceres.1996@uma.es, anjoa@uma.es
}

Scientific inquiry is ideal for learning science using recurring topics in early childhood education such as plants, since it makes it possible to work on science with groups of children who collaborate and can answer questions about the natural environment while sharing experiences.

This paper aims to show how to carry out an inquiry related to the germination and growth of plants with 3 -year-old students, and to document the progress that occurs in the conceptual understanding of plant growth. A simplified and recursive cycle of inquiry is used, which includes five phases: posing the problem and issuing hypotheses, design of the experiment, experimenting and manipulating, analysis of results and decision making, and conclusions. This investigation was implemented with eight children of 3 years old from an infant school in the province of Malaga and lasted 12 days.

The research starts with the problem: how do we grow a plant? Once the hypotheses were given, the teacher gave each child a plastic cup and different alternatives to design their experiment were offered. The children could choose between planting seeds or inert matter, wetting the cotton with water or not, or placing it in various areas of the classroom with different lighting. In successive days, the children continued to make decisions independently about the nature of the seed, form of irrigation or location.

The sequence presents for each phase the activities developed, and the questions asked in class, the objectives and the competencies related to the inquiry. The instruments used to gather the information were the oral responses of the children collected through audio and video recordings during the inquiry individually and in assembly, the observation diary of the two participating teachers and the daily tab for following-up the process that included pictograms for each growth factor.

Researchers explored the children's previous ideas and the goals achieved and not achieved with regards to the seed, the influence of light, water and plant parts for each phase. Progress is shown by finding that $62.5 \%$ of children recognize seed and water as necessary growth factors, and $37.5 \%$ also include sunlight. Although some children recognized that living matter, and not inert, is necessary for germination, others did not advance in this sense. The achievements made are relevant since some of these difficulties remain at 6-7 years of age, and in this case, some 3-year-old children were able to express it systematically in their conclusions.

Nevertheless, some aspects should continue to be worked on, such as the difficulty to adjust the adequate amount of water or to recognize sunlight as a factor responsible for growth, but not for germination. Another topic to reinforce is the children's acquisition of the scientific vocabulary involved. For instance, they are confused about the differences between seed and plant, about the names of the seed, as well as the identification of the parts of the plant. In that sense, they usually use the terms flowers and leaves to refer to many parts of the plant.

The research has also helped children to improve the scientific processes involved by enhancing observation and description (appearance of new plant parts, changes produced), making predictions, experimenting (watering, changing the plastic cup of place), collecting data (measuring stem height, counting the number of leaves), making decisions and issuing conclusions.

Finally, the collaboration of families in inquiries that require follow-up at home is essential, and teachers must inform families about their child's project and share how they work without interference. 
